\title{
A Neural Based Modeling Approach for Drying Kinetics Analysis of Mint Branches and Their Fractions (Leaves and Stems)
}

\author{
Aline de Holanda Rosanova1, Gustavo Dias Maia², Fábio Bentes Freire², \\ Maria do Carmo Ferreira ${ }^{2}$ \\ ${ }^{1}$ Graduate Program of Chemical Engineering, Federal University of São Carlos, São Carlos, Brazil \\ ${ }^{2}$ Chemical Engineering Department, Federal University of São Carlos, São Carlos, Brazil \\ Email: mariaf@ufscar.br
}

How to cite this paper: Rosanova, A.H., Maia, G.D., Freire, F.B. and Ferreira, M.C. (2017) A Neural Based Modeling Approach for Drying Kinetics Analysis of Mint Branches and Their Fractions (Leaves and Stems). Advances in Chemical Engineering and Science, 7, 154-174.

https://doi.org/10.4236/aces.2017.72012

Received: February 4, 2017

Accepted: March 10, 2017

Published: March 13, 2017

Copyright () 2017 by authors and Scientific Research Publishing Inc. This work is licensed under the Creative Commons Attribution International License (CC BY 4.0).

http://creativecommons.org/licenses/by/4.0/

\begin{abstract}
This work is aimed at investigating regular mint (Mentha $\times$ villosa) drying behavior and assessing how the heterogeneous composition of plants affects their drying kinetics. Drying kinetics and sorption isotherms were evaluated for whole branches and their fractions (leaves and stems). Stems and leaves were characterized by measurement of dimensions, apparent density and initial moisture content. The moisture sorption isotherms were obtained under temperatures of $30^{\circ} \mathrm{C}, 40^{\circ} \mathrm{C}$ and $50^{\circ} \mathrm{C}$ for branches, stems and leaves and the data were fitted to the $\mathrm{GAB}$ model. Mint branches and their fractions were oven dried at temperatures from $40^{\circ} \mathrm{C}$ to $70^{\circ} \mathrm{C}$ and were obtained kinetic curves for each part. Water sorption patterns were similar for leaves and stems and the GAB model described well the sorption behavior of both materials. At a constant temperature, the drying rates were higher for leaves in comparison to stems and the differences increased as the temperature was raised. Therefore, depending on drying conditions, the moisture distribution in dried branches might be significantly different. Since the leaves constitute the major fraction in branches, the drying rates of branches were closer to those of leaves. The kinetic curves were fitted to a diffusion model based on an analytical solution of Fick's second diffusion law and to an empirical model based on artificial neural network (ANN). The results showed that the model based on the ANN predicted the drying kinetics of the different parts better than the diffusive model. A single network was built to describe the kinetic behavior of branches and fractions in the whole range of temperatures investigated. The diffusive model based on fitting effective diffusivity did not provide good predictions of moisture content, probably because neither the dependence of effective diffusivity on the moisture content nor the heterogenei-
\end{abstract}


ty and shrinking of static beds were considered.

\section{Keywords}

Aromatic Herbs, Regular Mint, Branches, Stems, Sorption Isotherms, Oven Drying, Artificial Neural Network

\section{Introduction}

Fresh aromatic herbs have a significant amount of water, on average up to $80 \%$ in wet basis [1] [2]. The properties and stability features of plants are affected by the amount and state of water present in the material [3] and dehydration is a widely used method to preserve their quality for long times aiming at processing and storage. A considerable amount of research on hot air drying for different plant species is available in the literature, for a broad variety of equipment that include oven-dryers, conveyor belt and convective tunnel-dryers [4]. In these dryers, the herbs are arranged as one-layer samples and exposed to either free or forced convective air flow, and dried up to a suitable moisture content for storage. It is known that the drying rate is affected by numerous factors, including the dryer configuration, the process conditions, the herb physical-chemical properties and also the part of the plant to be dried [5].

The heterogeneity in the herbs' composition is an aspect often neglected in the analysis of their drying and is the focus of this research. The aerial part of aromatic plants is composed by two main fractions, which are the leaves and the stems. Bioactive compounds may be found in both, therefore, for trading purposes, it is usual drying the whole branches [6]. Because every fraction has a particular shape and size with different physical properties, moisture content and chemical composition, the drying rates may be quite different under similar process conditions. This may lead to non-uniformly dehydrated products when the parts are dried together [7]. The adequate equilibrium conditions for storage may also differ for leaves and stems because the state of water is established by complex interactions between the solid matrix and the water [3].

Although the prediction of drying kinetics is an important issue that reflects the accuracy of a drying process simulation, difficulties arise in the use of either purely mechanistic or empirical approaches. The significant shrinkage observed in dehydration of aromatic herbs and heterogeneity in their composition are major drawbacks to the use of phenomenological models. A lumped model based on the analytical solution of Fick's diffusion second law is often applied to describe drying kinetics [8] [9] [10], but although these complex processes can be mathematically described based on this approach, the fitted equations tend to be particular, making generalizations difficult.

Artificial neural networks may be an effective alternative to the mechanistic approach, since they can represent highly nonlinear processes. Furthermore, they are quite flexible and robust against input noise and, once developed and 
their coefficients determined, they can provide a rapid response for a new input [11] [12]. This technique has been successfully applied in different applications, such as to estimate the higher heating values of biomass fuels [13] or to predict air quality parameters [14], its use in drying applications is still incipient. Freire et al. [15] discuss various applications involving control and sensing techniques for spouted bed drying including adaptive and neural based algorithms. Hybrid neural network and first principle models, also known as grey-box models as opposed to black box where no model form is assumed or white box models that are purely theoretical, can likewise be found in the literature [16] [17] [18] [19]. ANNs are a computation method of programming that mimics the human brain, i.e. they are formed by various units, called artificial neurons, which may correlate databases between themselves [20] [21]. Figure 1 shows a typical structure of a three layers neural network.

The computational capability of ANNs results from their ability to learn from examples through iteration, without requiring a prior knowledge of relationships between the variables under investigation [21] [22]. This technique is based on a trial and error fitting procedure until reaching a good agreement to the output parameters in a specified accuracy range [20] [21]. The network design may be adapted or modified to meet the specific requirements of each particular case by varying the number of neurons and neuron layers, which results in many different possible structures that allow the construction of very flexible models [19].

The aims of this work were to evaluate the sorption behavior and to present an analysis of both neural networks and mechanistic models focused on showing their suitability to fit and predict drying kinetics of mint (Mentha $x$ villosa) leaves, stems and branches containing a mixture of both, leaves and stems. The sorption data were obtained under temperatures of $30^{\circ} \mathrm{C}, 40^{\circ} \mathrm{C}$ and $50^{\circ} \mathrm{C}$ and fitted to the $\mathrm{GAB}$ model, whose fitted parameters were analyzed to assess the water properties and energy requirements associated to their desorption behavior. With regards to drying behavior, simulations were carried out in MatLab ${ }^{\circ}$ (R2013a, Mathworks) with a database from experiments in a drying chamber at four different temperatures: $40^{\circ} \mathrm{C}, 50^{\circ} \mathrm{C}, 60^{\circ} \mathrm{C}$ and $70^{\circ} \mathrm{C}$. Results of

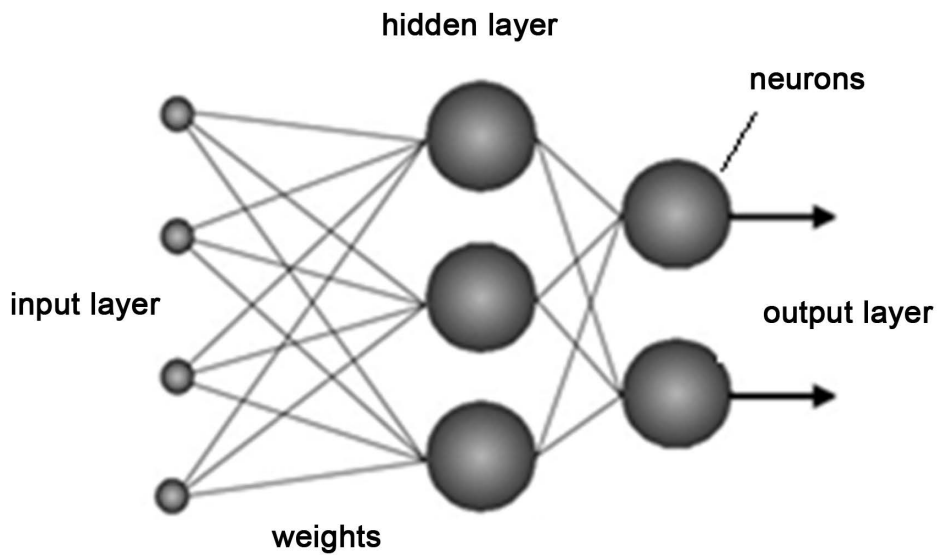

Figure 1. Three layers neural network. 
model verification showed that both approaches may be used to predict drying kinetics outside the database, however, the artificial neural network was superior in all instances.

\section{Materials and Methods}

\subsection{Material}

Fresh regular mint (Mentha $\times$ villosa) branches were purchased from a local market located in the city of São Carlos-Brazil. Uniform branches based on color, growth stage and absence of injuries were selected. The material was washed in water and the water excess was removed using a soft paper. Finally, the branches were cut into 2 to 3 length pieces to be used in the experiments (characterization, drying or sorption isotherm).

\subsection{Regular Mint Characterization}

The leaves and stems of fresh mint were characterized by measuring their moisture content, apparent density and dimensions. The moisture content was determined by the standard gravimetric method $\left(105^{\circ} \mathrm{C} \pm 3^{\circ} \mathrm{C}\right.$ during $\left.24 \mathrm{~h}\right)$ [23], and the apparent density by liquid picnometry using toluene as immersion liquid [23]. These properties were measured in triplicate for each material.

Samples containing 90 leaves or 90 stems were selected and their length, thickness, diameter, width and projected area were measured using the software Image-Pro Plus 6. The measured dimensions were used to calculate the leaves' and stems' superficial area, volume and sphericity. The sphericity of leaves and stems were calculated as the ratio of the three perpendicular axes average dimension over the major axis dimension [24].

\subsection{Drying Experiments}

Drying experiments were conducted separately, for samples of leaves, stems and whole branches, in a natural convection oven dryer under temperatures of $40^{\circ} \mathrm{C}$, $50^{\circ} \mathrm{C}, 60^{\circ} \mathrm{C}$ and $70^{\circ} \mathrm{C}$. Samples containing $15 \mathrm{~g}$ of fresh leaves, stems or branches were uniformly distributed over perforated trays in a $1 \mathrm{~cm}$ high layer. The trays were placed into an oven (Tecnal model TE-394) with controlled temperature at an accuracy of $\pm 1^{\circ} \mathrm{C}$, under free convective air flow.

The moisture loss was recorded periodically by weighing the trays on a digital balance with $0.001 \mathrm{~g}$ accuracy (Gehaka model BG 440), until reaching a constant mass. The moisture content of leaves, stems and branches were determined by the gravimetric method [23]. The experiments were carried out in replicates. Kinetic curves were obtained by plotting the dimensionless moisture ratio (MR), defined by Equation (1) as a function of time.

$$
M R=\frac{\left(M_{t}-M_{e}\right)}{\left(M_{i}-M_{e}\right)}
$$

where, $M_{t}$ is the moisture content at a specific time, $M_{i}$ is the initial moisture content and $M_{e}$ is the equilibrium moisture content, given in $\mathrm{kg}$ of moisture $/ \mathrm{kg}$ 
of dry matter and estimated from GAB equation with fitted parameters.

\subsection{Desorption Isotherms Experiments}

The desorption isotherms of leaves, stems and branches were determined by the standard static gravimetric method. This technique is based on using some saturated solutions to maintain the samples in an environment with constant temperature and relative humidity [3]. In this study, the experiments were conducted with $2 \mathrm{~g}$ of leaves, stems or branches, which were held in small glass vessels of $8.5 \mathrm{~cm}$ of diameter and $13.5 \mathrm{~cm}$ of height with insulated lid. Each vessel contained a different saturated solution corresponding to a range of water activity from 0.057 to 0.834 (Table 1). The samples were inserted in perforated plastic cups and were attached to the top of the vessels to avoid any contact with the saturated solutions.

The vessels were stored in a climatic chamber (Binder), at temperatures of $30^{\circ} \mathrm{C}, 40^{\circ} \mathrm{C}$ or $50^{\circ} \mathrm{C}$ during 20 days. After this time, the samples were weighted in a balance with accuracy of $0.001 \mathrm{~g}$ (AND model HR-120) every four days until a constant mass was reached. The final moisture content of each sample was determined by oven drying the samples (leaves, stems or branches) at $105^{\circ} \mathrm{C}$ for 24 $\mathrm{h}$ [23]. The experiments were carried out in replicates.

\subsection{Modeling}

\subsubsection{Drying Model Based on Fick's Diffusive Model}

The data of moisture versus time were fitted to a model based on the Fick's second law of diffusion [27]:

$$
\frac{d M}{d t}=D \frac{d^{2} M}{d x^{2}}
$$

where $\mathrm{M}$ is the local moisture content ( $\mathrm{kg}$ of moisture/kg of dry matter), $\mathrm{x}$ is the diffusion path (m), $t$ is the time (s), and $\mathrm{D}$ is the moisture diffusivity $\left(\mathrm{m}^{2} / \mathrm{s}\right)$.

This model assumes that the drying during the falling rate period is controlled by the mechanisms of liquid-vapor diffusion and occurs in only one direction;

Table 1 . Water activity of saturated solutions at $30^{\circ} \mathrm{C}, 40^{\circ} \mathrm{C}$ and $50^{\circ} \mathrm{C}$ [25] [26].

\begin{tabular}{cccc}
\hline \multirow{2}{*}{ Compound } & \multicolumn{3}{c}{ Water activity } \\
\cline { 2 - 4 } & $30^{\circ} \mathrm{C}$ & $40^{\circ} \mathrm{C}$ & $50^{\circ} \mathrm{C}$ \\
\hline $\mathrm{KOH}$ & 0.074 & 0.063 & 0.057 \\
$\mathrm{CH}_{3} \mathrm{COOK}$ & 0.216 & 0.204 & 0.192 \\
$\mathrm{MgCl}_{2}$ & 0.324 & 0.316 & 0.305 \\
$\mathrm{~K}_{2} \mathrm{CO}_{3}$ & 0.432 & 0.432 & 0.433 \\
$\mathrm{Mg}\left(\mathrm{NO}_{3}\right)_{2}$ & 0.514 & 0.484 & 0.454 \\
$\mathrm{NaNO}_{2}$ & 0.635 & 0.616 & 0.597 \\
$\mathrm{NaCl}$ & 0.751 & 0.747 & 0.744 \\
$\mathrm{KCl}$ & 0.836 & 0.823 & 0.812 \\
\hline
\end{tabular}


that the sample layers are homogeneous and the moisture diffusivity does not depend on the moisture content [27] [28]. For flat slab-shaped samples under uniform initial moisture content, and assuming that the resistance to mass transfer at the surface of the sample is negligible in comparison to the internal resistance, the analytical solution of Equation (2) was obtained by Crank [29] and is given by Equation (6) for the following initial condition and boundary conditions:

$$
\begin{aligned}
& t=0,0<x<L, M=M_{i} \\
& t>0, x=0, \frac{d M}{d x}=0 \\
& t>0, x=L, M=M_{e}
\end{aligned}
$$

where $L$ is the thickness (m) of the sample.

$$
M R=\frac{8}{\pi} \sum_{n=1}^{\infty} \frac{1}{(2 n-1)^{2}} \exp \left[\frac{-(2 n-1)^{2} \pi^{2} D_{\text {eff }} t}{4 L^{2}}\right]
$$

where $M_{t}$ is the average moisture content at any time ( $\mathrm{kg}$ of moisture $/ \mathrm{kg}$ of dry matter), $D_{\text {eff }}$ is the effective diffusivity coefficient $\left(\mathrm{m}^{2} / \mathrm{s}\right)$ and $\mathrm{L}$ is the sample thickness. The effective diffusivity replaces the ordinary diffusion coefficient to take into account other moisture transport mechanisms that appear in porous materials, such as capillary flow, Knudsen flow, hydrodynamic flow or surface diffusion [4]. The $\mathrm{D}_{\text {eff }}$ values were fitted from Equation (6) with $\mathrm{n}=100$, using the Solver routine available in software Microsoft Excel.

\subsubsection{Desorption Isotherms}

A water sorption isotherm is a fundamental relationship that describes the dependence of water content within a solid-water mixture on the water activity, at a certain pressure and temperature [30]. The Guggenheim, Anderson and de Boer (GAB) model (Equation (7)) is recommended as a versatile and suitable model to predict the sorption data in a wide range of water activities [29] and was used to describe the sorption data in this study. This model is relevant because their three parameters $\left(X_{m}, K\right.$ and $C_{g}$ ) may be physically interpreted, which may be very useful in the analysis of sorption processes [3] [31].

$$
\frac{X}{X_{m}}=\frac{C_{g} K a_{w}}{\left(1-K a_{w}\right)\left(1-K a_{w}+C_{g} K a_{w}\right)}
$$

The theoretical basis of GAB model is the consideration of physical adsorption of water in multilayers with no lateral interactions. In this concept, a first layer of tightly bound water, which is called a monolayer, uniformly covers the surface of the absorbent material. Additional water molecule layers will coat this first layer, forming several levels in which the water interaction with the adsorbent surface becomes progressively weaker. Therefore, the binding energy between the adsorbent surface and water will decrease from the strong binding energy at the monolayer to zero at the outer layers. In the outer layers, far from the adsorbent surface, the water molecules show properties similar to those of 
liquid water [30].

Each parameter in GAB's model has a physical meaning associated to the water state in the mono or multilayers. Owing to that, the values of parameters $X_{m}$, $K$ and $C_{g}$ should be restricted, so that $X_{m}$ and $C_{g}$ must be greater than 0 and 1 respectively, and $K$ must range from 0 to 1 [3]. $X_{m}$ is known as the monolayer moisture content and it is interpreted as a measure of the number of active sites available for water sorption in the material. The value of this parameter is expected to decrease as the temperature is increased, due to the destruction of the active sites available for water sorption [30]. The parameters $\mathrm{C}_{\mathrm{g}}$ and $K$ represent the nature of the water-material interaction. $\mathrm{C}_{\mathrm{g}}$ is a measure of the strength of water binding to the primary binding sites. It is expected to decrease as the temperature rises, since at higher temperatures more energy is provided to the material, facilitating the water removal. Finally, $K$ characterizes the properties of multilayer water in comparison to free liquid water and its value should increase with increasing temperature. A value of $\mathrm{K}$ close to 1 means that there is almost no difference between water in the multilayer and liquid water and then it can be considered that the molecules of water located above the monolayer are not structured in a multilayer [3].

\subsubsection{Artificial Neural Network}

The first step in designing a neural network is to select its basic structure, with given neurons and hidden layers between the input and the output. A typical input/output relationship of a neural network with a single hidden layer is given by:

$$
y=b_{2}+L W \cdot \operatorname{tansig}\left(b_{1}+I W \cdot x\right)
$$

where $y$ is an output vector, $x$ is an input vector, $L W$ is the connection matrix of weights corresponding to all the arcs from the hidden layer to the output layer, IW is the connection matrix from the input layer to the hidden layer, $b_{1}$ and $b_{2}$ are the bias vectors for the hidden and output layers, respectively.

In a feed forward neural network, the signal received by the intermediate (hidden) layer goes to the neurons of the output layer. In the hidden layer, in turn, each unit $\left(Y_{j}\right)$ sums its weighted inputs and applies the activation function to generate the output signal according to:

$$
Y_{j}=\mathrm{f}_{\mathrm{act}}\left(\sum_{i=1} W_{i j} X_{i}+b_{j}\right)
$$

where $W_{i j}$ is the weight of the connection between the i-th input and the j-th neuron of the hidden layer and $b_{i}$ if the bias weight of the unit $\mathrm{j}$. The activation function used in this work is the tan-sigmoidal, given by:

$$
\mathrm{f}_{\mathrm{act}}(\mathcal{X})=\frac{1}{1+e^{-\mathcal{X}}}
$$

The output from neuron $Y_{j}$ is sent to all units of the output layer, Each output neuron $O_{k}$ sums the weighted input signal and applied the activation function according to: 


$$
O_{k}=\mathrm{f}_{\mathrm{act}}\left(\sum_{j=1} V_{j k} Y_{j}+b_{k}\right)
$$

The weights $W_{i j}$ of each connection between neurons in adjacent layers are determined during the network learning process. The initial values of weights are aleatory chosen, but since the results converge to a local minimum, the initial values do not influence the results. The learning process uses nonlinear optimization algorithms to correct the weights and, once a network has been trained, it can provide a response with few simple calculations, which is one of the advantages of using a neural network instead of fully theoretical differential models. A key difficulty with optimization to determine the neural network weights is that multiple minima occur in the objective function used. Consequently, satisfactory representation of data rests on the use of the best local minimum that can be achieved in a reasonable time.

Like any data fitting technique, the neural network is also evaluated on the ability to fit the training data and predict outside the training set. An appropriate neural network should exhibit good generalization for few data and computational efficiency, which means that the smaller the network, the fewer the parameters and the data required and the shorter the identification time involved. In practice, smaller ANNs are easier to train and thus perform better, and can also be more easily scaled to more complex problems. Therefore, in this work, the design of the neural network was done in the Neural Network Toolbox for use with MatLab. MatLab Neural Network Toolbox allowed for fast model creation and validation in a single framework. Standard Bayesian regularization back propagation training algorithm was used for training the network. This training algorithm updated the weights between adjacent neurons according to the Levenberg-Marquardt algorithm. It minimizes a linear combination of squared errors multiplied by weights to produce a network that best fits the experimental data. The number of neurons in the hidden layer was chosen by trial and error, as suggested by Himmelblau [11] starting with 2 neurons and adding up some more until the network performance in estimating the correct output is satisfactory. A reasonable number of neurons for this application was found to be 4 .

\section{Results and Discussions}

\subsection{Physical Properties}

The photograph of a whole branch of regular mint shown in Figure 2 illustrates the differences of leaves and stems shape and sizes. It can be seen that the leaves are flat-shaped and thin, while the stem has a cylindrical shape. Their structures are also different, because the leaves are fragile and flexible, and the stem is more rigid and firm.

The main dimensions, apparent density and moisture content of fresh regular mint leaves and stems are presented in Table 2.

The moisture content of fresh leaves is slightly lower and the apparent density is about $10 \%$ higher than that of stems. Both fractions have a low sphericity, 


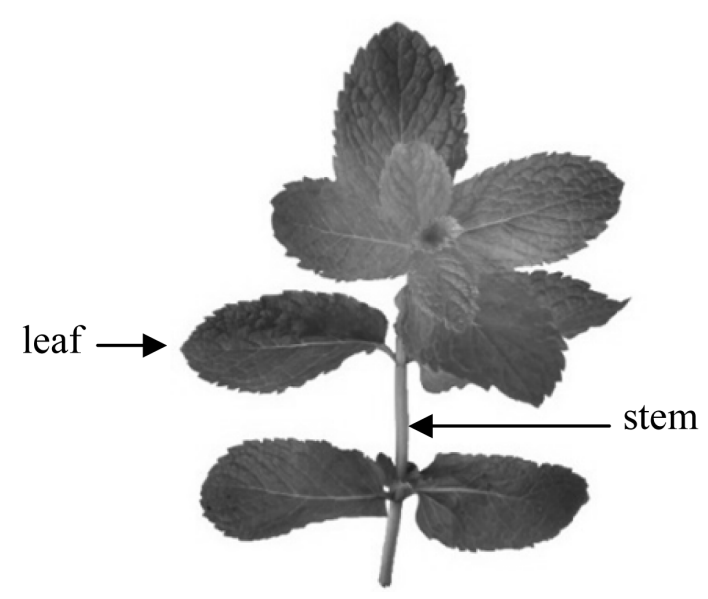

Figure 2. Photograph of a regular mint whole branch.

Table 2. Physical properties of fresh regular mint leaves and stems.

\begin{tabular}{ccc}
\hline & Leaves & Stems \\
\hline Moisture content $(\mathrm{db})$ & $6 \pm 1$ & $10 \pm 3$ \\
Apparent density $\left(\mathrm{g} / \mathrm{cm}^{3}\right)$ & $0.86 \pm 0.02$ & $0.79 \pm 0.01$ \\
Sphericity & $0.12 \pm 0.01$ & $0.22 \pm 0.03$ \\
Thickness $(\mathrm{mm})$ & $0.18 \pm 0.02$ & - \\
Diameter $(\mathrm{mm})$ & - & $2.5 \pm 0.5$ \\
Width $(\mathrm{mm})$ & $3.5 \pm 0.4$ & - \\
Length $(\mathrm{mm})$ & $6.1 \pm 0.8$ & $2.4 \pm 0.2$ \\
Projected area $\left(\mathrm{cm}^{2}\right)$ & $16 \pm 3$ & $0.7 \pm 0.2$ \\
Superficial area $\left(\mathrm{cm}^{2}\right)$ & $33 \pm 7$ & $2.0 \pm 0.5$ \\
Volume $\left(\mathrm{cm}^{3}\right)$ & $0.29 \pm 0.07$ & $0.12 \pm 0.06$ \\
\hline
\end{tabular}

which is consistent with the cylindrical-shaped format of the stems, and the flat and slab-shaped format of leaves. In the values of sphericity, apparent density and length of both materials, the standard deviations are small (under 10\%). However, it can be noted that in general the standard deviations in the measurements of the stems' properties were significantly higher than those of leaves. These deviations reached values of $50 \%$ in the volume values, $30 \%$ in the moisture content, $28 \%$ in the projected area, $25 \%$ in the superficial area and $23 \%$ in the width. Regarding to the leaves, the standard deviations were high only in the volume (24\%), projected and superficial areas (about 20\%) and moisture content (16\%). In fact, a wide size distribution is expected in samples of both fractions, considering the natural variability in dimensions of biological materials. The higher deviation in the stems physical properties is probably because their dimensions tend to change more depending on their growth stage and position in the branch.

It is worth noting the low superficial area of stems $\left(2 \mathrm{~cm}^{2}\right) \mathrm{n}$ comparison to leaves $\left(33 \mathrm{~cm}^{2}\right)$ and the very distinct ratios of area to volume which is $114 \mathrm{~cm}^{-1}$ for the leaves and only $17 \mathrm{~cm}^{-1}$ for the stems. 


\subsection{Sorption Isotherms}

The desorption isotherms of leaves, stems and branches of regular mint, determined at $40^{\circ} \mathrm{C}$ are shown in Figure 3. It shows that the isotherms of the three materials have a sigmoid shape (type II isotherms), which is a characteristic shape for biological materials [3].

The results for branches and their fractions are similar throughout the range of water activity evaluated, except for the higher values of water activity, where the stems presented slightly higher equilibrium moistures in comparison to leaves and branches. This behavior indicates that under equilibrium conditions at a given temperature, the interaction between the water and the materials are similar for leaves and stems, in spite of their differences in structure and composition. As for the other evaluated temperatures $\left(30^{\circ} \mathrm{C}\right.$ and $\left.50^{\circ} \mathrm{C}\right)$, the behavior was similar to that observed at $40^{\circ} \mathrm{C}$, these results will not be showed for the sake of being concise.

To analyze the influence of temperature on desorption isotherms of regular mint fractions, in Figure 4 are presented the isotherms obtained for leaves and stems under the temperatures of $30^{\circ} \mathrm{C}, 40^{\circ} \mathrm{C}$ and $50^{\circ} \mathrm{C}$.

At a given water activity, the equilibrium moisture content of leaves decreases with increasing the temperature (Figure 4(a)). Leaves are very sensitive to high temperatures and shrink considerably when dryer. The increase in the temperature contributes to changing the structure of the material, destroying some active sites available for water sorption. Moreover, the binding energy between the water molecules and the solid is reduced at a higher temperature. As the water molecules become less stable, they break away from the water binding sites, which also contributes to reducing the equilibrium moisture content of leaves [3] [30]. The dependence of equilibrium moisture content on the temperature was not observed in the desorption isotherms of stems (Figure 4(b)). This behavior is probably because the structure of the stems are better preserved in this range

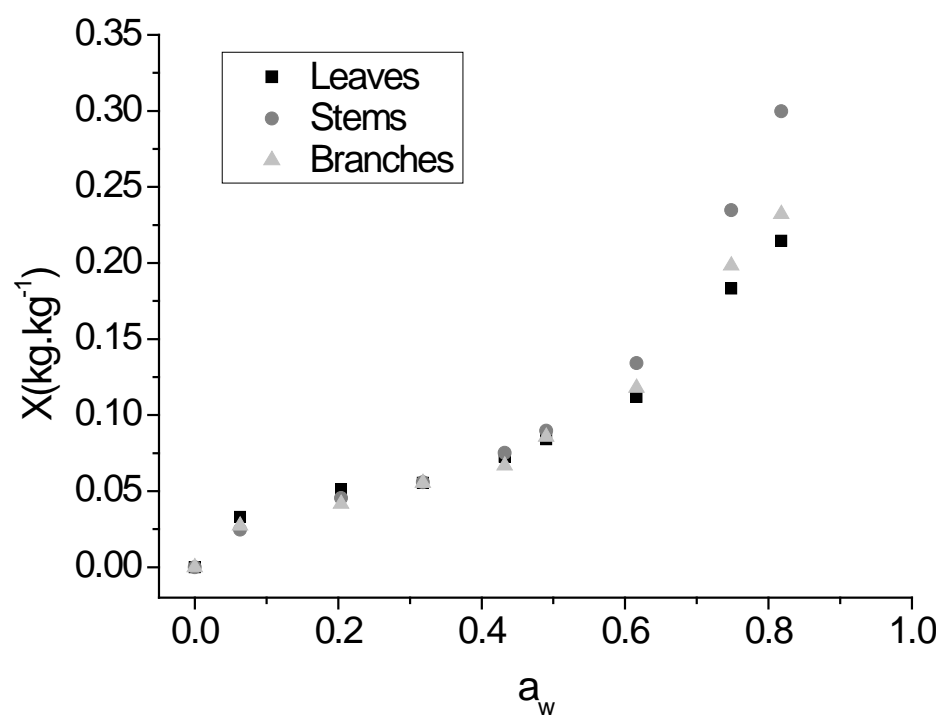

Figure 3. Desorption isotherms of leaves, stems and branches of regular mint at $40^{\circ} \mathrm{C}$. 


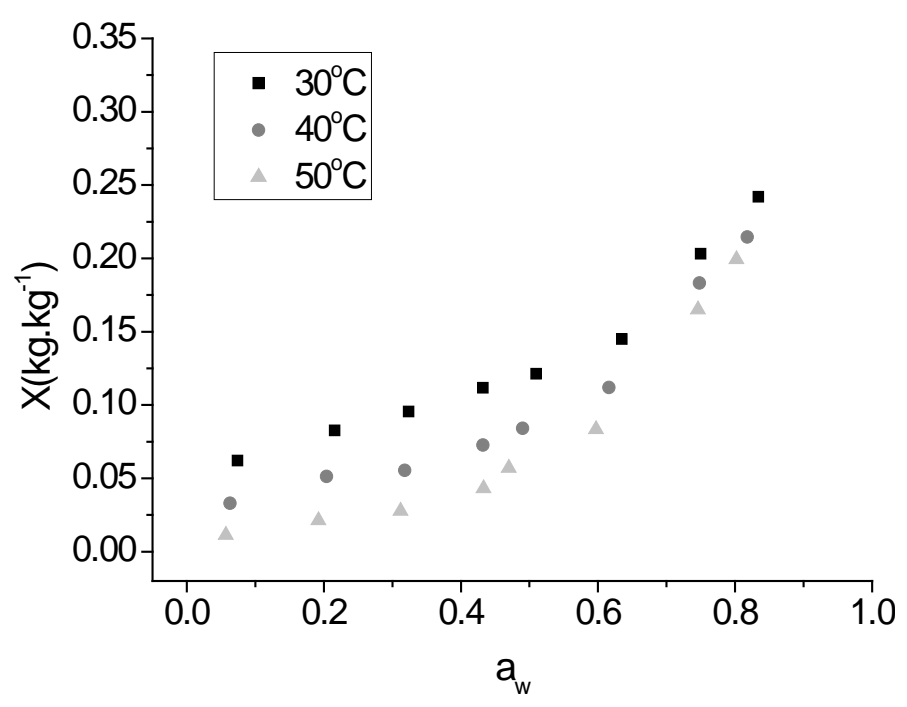

(a)

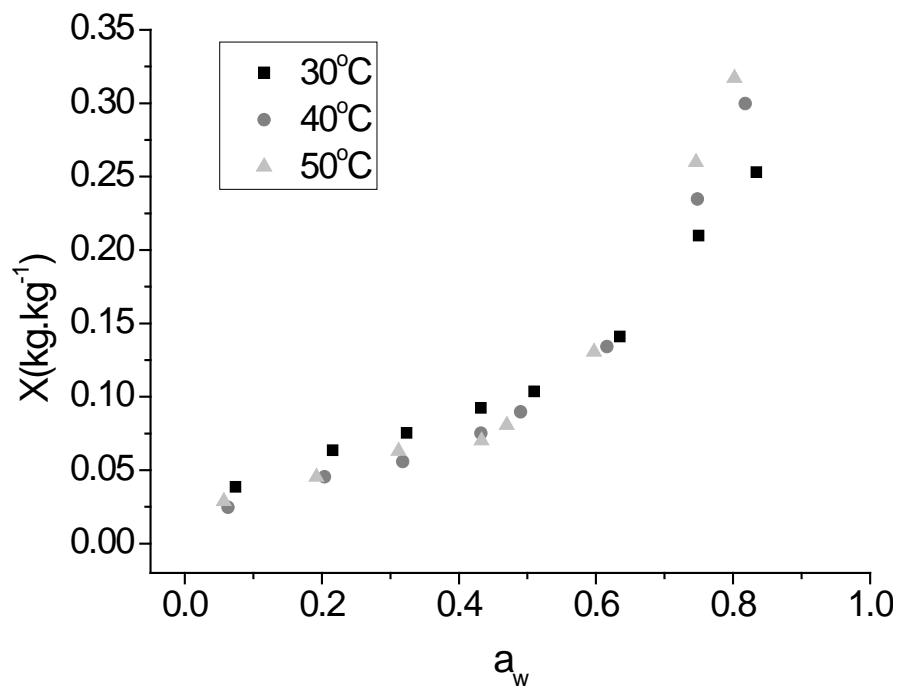

(b)

Figure 4. Desorption isotherms of (a) leaves and (b) stems at temperatures of $30^{\circ} \mathrm{C}, 40^{\circ} \mathrm{C}$ and $50^{\circ} \mathrm{C}$.

of temperatures, since they have a more rigid structure in comparison to the leaves. Therefore, the increase in the temperature possibly did not affect significantly the amount of water physically adsorbed on the stems, leading to similar equilibrium moisture contents under the three temperatures evaluated.

The results obtained for the whole branches showed a similar behavior to that of the leaves. Since the samples of branches used in these assays were composed of about $76 \%$ of leaves and $24 \%$ of stems (weight basis), this similarity was already expected.

Figure 5 shows the fitted equations in comparison to the experimental isotherms of leaves and stems, under temperatures of $30^{\circ} \mathrm{C}, 40^{\circ} \mathrm{C}$ and $50^{\circ} \mathrm{C}$ and the fitted parameters of GAB model for whole branches, leaves and stems can be seen in Table 3. 


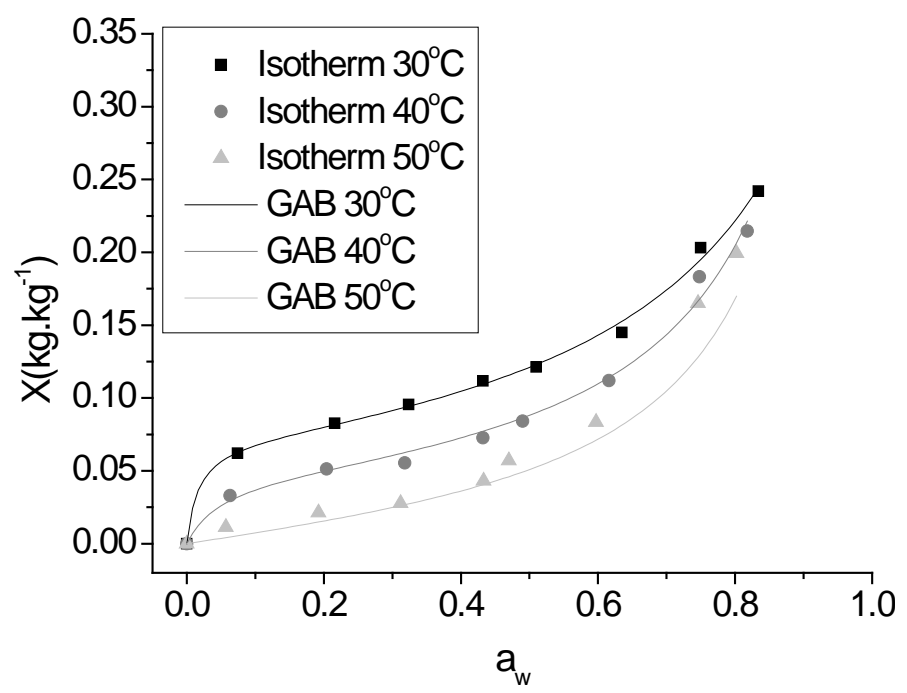

(a)

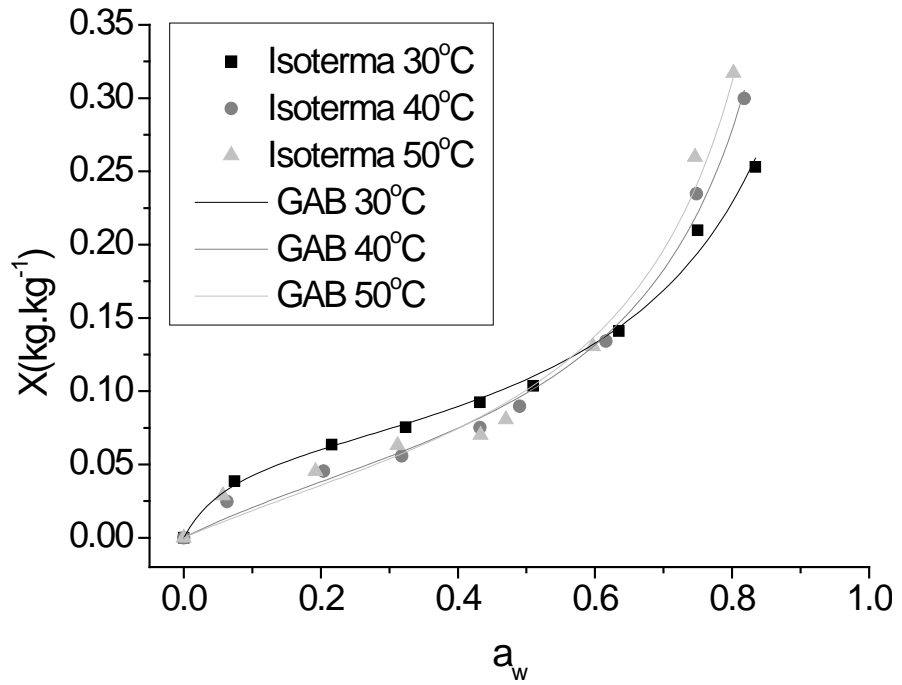

(b)

Figure 5. Desorption isotherms fitted equations for regular mint (a) leaves and (b) stems.

Table 3. Estimated parameters in GAB model and determination coefficients for desorption isotherms of leaves, stems and branches of regular mint at $30^{\circ} \mathrm{C}, 40^{\circ} \mathrm{C}$ and $50^{\circ} \mathrm{C}$.

\begin{tabular}{cccccc}
\hline \multirow{3}{*}{ Leaves } & & $\mathrm{X}_{\mathrm{m}}$ & $\mathrm{C}_{\mathrm{g}}$ & $\mathrm{K}$ & $\mathrm{R}^{2}$ \\
\hline \multirow{5}{*}{ Stems } & $30^{\circ} \mathrm{C}$ & 0.071 & 71.59 & 0.85 & 0.996 \\
& $40^{\circ} \mathrm{C}$ & 0.048 & 20.88 & 0.96 & 0.987 \\
& $50^{\circ} \mathrm{C}$ & 0.040 & 1.84 & 0.99 & 0.911 \\
& $30^{\circ} \mathrm{C}$ & 0.063 & 15.43 & 0.91 & 0.991 \\
& $40^{\circ} \mathrm{C}$ & 0.064 & 3.75 & 0.98 & 0.991 \\
& $50^{\circ} \mathrm{C}$ & 0.067 & 2.96 & 1.00 & 0.982 \\
& $30^{\circ} \mathrm{C}$ & 0.065 & 41.86 & 0.89 & 0.994 \\
& $40^{\circ} \mathrm{C}$ & 0.057 & 5.57 & 0.95 & 0.991 \\
& $50^{\circ} \mathrm{C}$ & 0.052 & 2.29 & 0.99 & 0.978 \\
\hline
\end{tabular}


For both materials, under the temperatures evaluated, the GAB model fitted well the experimental data, with correlation coefficients greater than 0.91. According to Table 3, for leaves and branches the value of parameter $\mathrm{X}_{\mathrm{m}}$ increases with increasing temperature, while for stems it remains almost constant. These results corroborate the previous analysis suggesting that the leaf structure is affected by the increasing temperature, while the stem structure tends to remain preserved. The parameter $C_{g}$ was greater than 1 for the whole temperature range, indicating that the monolayer is formed by water tightly bound to the primary sorption sites. $\mathrm{C}_{\mathrm{g}}$ decreases with increasing temperature, which was expected once the monolayer presents higher energy levels at higher temperatures and the water tends to remain in the multilayer. The values of $K$ between 0 and 1 confirm that fitted parameters are consistent with their physical meanings. The values are close to 1 at temperatures of $40^{\circ} \mathrm{C}$ and $50^{\circ} \mathrm{C}$, which means that water in the multilayer is energetically similar to free liquid water at the same temperature, and that the energy required to remove this water from leaves and stems is similar.

Finally, a qualitative evaluation of the fitted parameters indicates that the monolayer moisture content in the three materials in very small (less than 0.071 in dry basis), indicating that even in the smallest water activity, the desorption process essentially occurred in the multilayer.

\subsection{Drying Kinetics}

The drying kinetics of regular mint leaves and stems at temperatures of $40^{\circ} \mathrm{C}$, $50^{\circ} \mathrm{C}, 60^{\circ} \mathrm{C}$ and $70^{\circ} \mathrm{C}$ can be observed in Figure 6, which depicts curves of moisture ratio versus drying time.

Figure 6 shows that the drying of leaves and stems are affected differently by the increase in the temperature and that the drying process occurred predominantly at a decreasing rate for all conditions evaluated. It can be noted that the drying rate of stems decreased gradually as the temperature was raised from $40^{\circ} \mathrm{C}$ to $70^{\circ} \mathrm{C}$, while the drying rate of leaves showed a sharp increase as the temperature raised from $40^{\circ} \mathrm{C}$ to $50^{\circ} \mathrm{C}$, and then it gradually increased from $50^{\circ} \mathrm{C}$ to $70^{\circ} \mathrm{C}$. This behavior was also observed in drying whole regular mint branches. The increase in temperature from $40^{\circ} \mathrm{C}$ to $70^{\circ} \mathrm{C}$ reduced the drying time in $80 \%$ for leaves, $68 \%$ for stems, and $71 \%$ for whole branches.

A comparison of drying kinetics for the branches, leaves and stems at temperatures of $40^{\circ} \mathrm{C}$ and $60^{\circ} \mathrm{C}$ can be seen in Figure 7 .

It can be observed that at $40^{\circ} \mathrm{C}$ (Figure $7(\mathrm{a})$ ) the curves obtained for branches, leaves and stems are similar, and particularly at the beginning of drying, the differences are within the range of measurements uncertainties. At $60^{\circ} \mathrm{C}$ (Figure 7(b)) the leaves are dried at higher rates than the stems, while the whole branches are dried at similar rates to those of the leaves. This behavior was reproduced at the temperatures of $50^{\circ} \mathrm{C}$ and $70^{\circ} \mathrm{C}$. The similarity in the drying kinetics of leaves and whole branches is explained because the branches used in the experiments were composed of approximately $80 \%$ of leaves in a weight basis. 


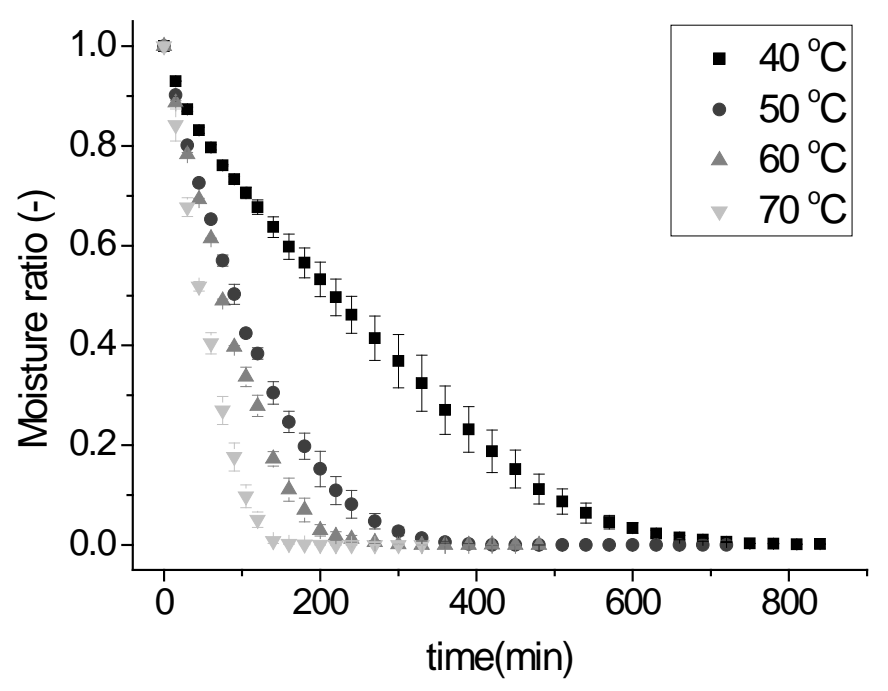

(a)

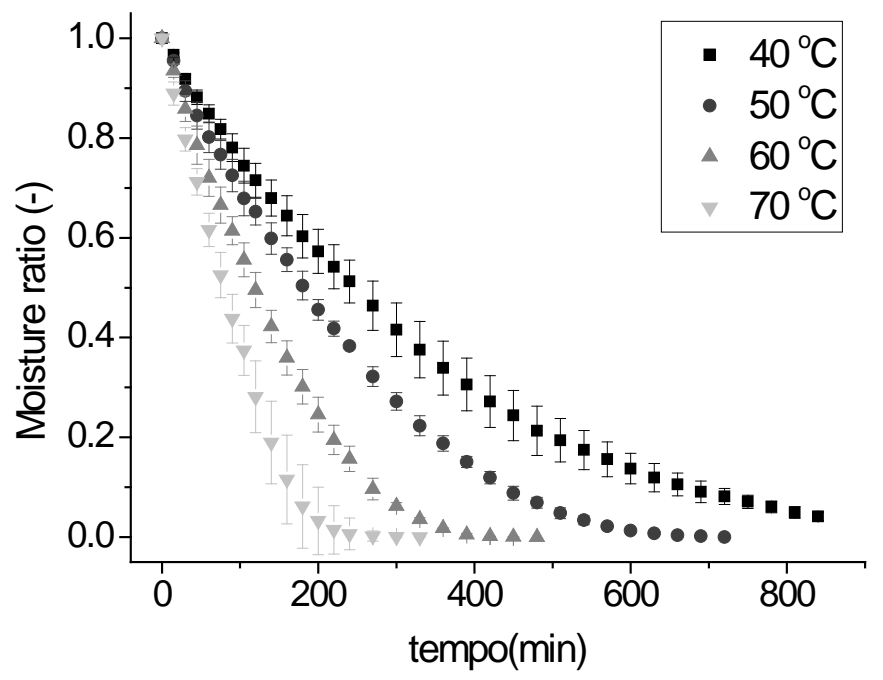

(b)

Figure 6. Moisture ratio versus time in drying (a) leaves and (b) stems under different temperatures.

Analysis of sorption isotherms showed that the multilayer water, which is predominantly removed in drying, is energetically similar to free liquid water and that the energy required to remove it from leaves and stems is similar. Therefore, the differences in drying kinetics of leaves and stems can be attributed to factors related to water transport mechanisms within the materials. It is known that heat and mass transfer are processes strongly favored by the contact area. As shown in Table 2, the surface area of leaves is one order of magnitude higher than that of the stems. Furthermore, the flat-shaped format of leaves, with a high ratio of area to volume, also favors an effective contact with hot air in drying. Since drying occurred at decreasing rates, the diffusive mechanisms limit the water transport. They are also enhanced by the very small thickness of the leaves $(0.18 \mathrm{~mm})$, while the average characteristic dimension of the stems is much larger $(1.25 \mathrm{~mm})$. 


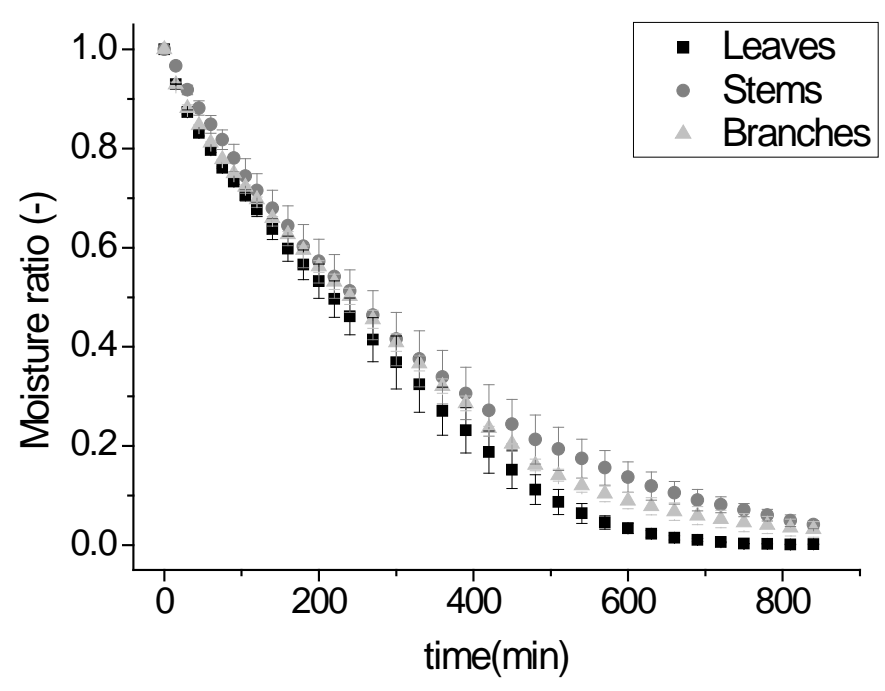

(a)

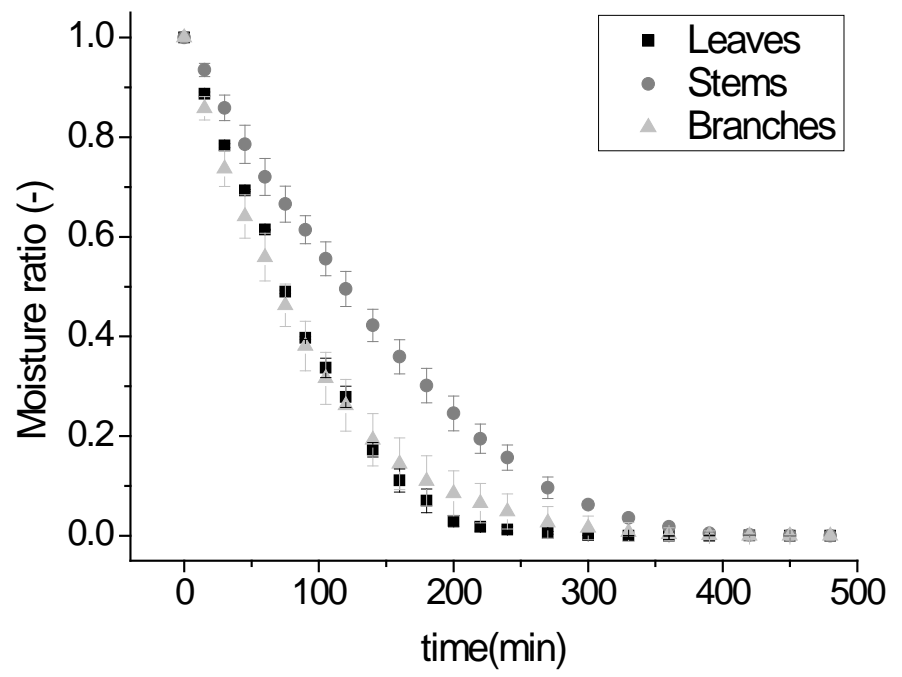

(b)

Figure 7. Moisture ratio versus time in drying regular mint branches and their fractions at (a) $40^{\circ} \mathrm{C}$ and (b) $60^{\circ} \mathrm{C}$.

\subsubsection{Effective Diffusivities}

The experimental data of moisture ratio versus time were fitted to Equation (6), and the effective diffusivity values were calculated for leaves, stems and branches at temperatures of $40^{\circ} \mathrm{C}, 50^{\circ} \mathrm{C}, 60^{\circ} \mathrm{C}$ and $70^{\circ} \mathrm{C}$. The fitted values of effective diffusivities are shown in Table 4, and a comparison of experimental and predicted values of moisture ratio versus time at $50^{\circ} \mathrm{C}$ can be seen in Figure 8.

Based on the curves shown in Figure 8 and on the low values of the determination coefficients in Table 4 (generally less than 0.92), it can be inferred that Equation (6) is not a good model to predict the drying kinetic of leaves, stems and branches of regular mint. The poor agreement may be explained, since some important assumption of this model are not satisfied in drying plants. One of them is that the bed of material behaves as a homogeneous solid throughout drying, which is clearly untrue. In fact, the leaves, stems and branches shrink 


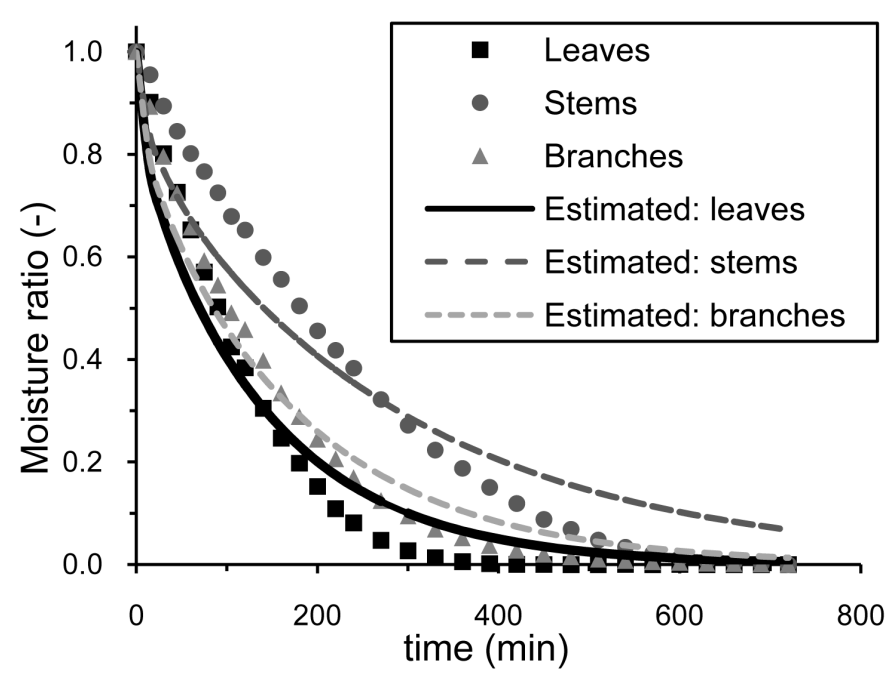

Figure 8. Moisture ratio versus time for leaves, stems and branches at $50^{\circ} \mathrm{C}$ : model based on Equation (7).

Table 4. Values of effective diffusivity and determination coefficients obtained from the fit o regular mint leaves and stems drying data to a model based on the Fick's second law of diffusion.

\begin{tabular}{cccc}
\hline & & Leaves & Stems \\
\hline $40^{\circ} \mathrm{C}$ & $\mathrm{D}_{\text {eff }}\left(\mathrm{m}^{2} / \mathrm{s}\right)$ & $5.07 \times 10^{-10}$ & $4.00 \times 10^{-10}$ \\
& $\mathrm{R}^{2}$ & 0.979 & 0.987 \\
$50^{\circ} \mathrm{C}$ & $\mathrm{D}_{\text {eff }}\left(\mathrm{m}^{2} / \mathrm{s}\right)$ & $1.17 \times 10^{-9}$ & $5.82 \times 10^{-10}$ \\
& $\mathrm{R}^{2}$ & 0.979 & 0.981 \\
$60^{\circ} \mathrm{C}$ & $\mathrm{D}_{\text {eff }}\left(\mathrm{m}^{2} / \mathrm{s}\right)$ & $1.524 \times 10^{-9}$ & $9.133 \times 10^{-10}$ \\
& $\mathrm{R}^{2}$ & 0.965 & 0.972 \\
$70^{\circ} \mathrm{C}$ & $\mathrm{D}_{\text {eff }}\left(\mathrm{m}^{2} / \mathrm{s}\right)$ & $2.47 \times 10^{-9}$ & $1.46 \times 10^{-9}$ \\
& $\mathrm{R}^{2}$ & 0.962 & 0.958 \\
\hline
\end{tabular}

considerably during drying, and their sizes and shapes change expressively, as could be observed in the experiments and has been already demonstrated in previous research [32]. This behavior leads to highly heterogeneous packed-beds, whose structure changes considerably over the drying time. Besides, the effective diffusivity of biological materials in a function of moisture content, and not constant as assumed in Equation (6).

However, the fitted values of effective diffusivity in Table 4 can be used to provide a rough estimate of diffusive resistances for leaves and stems, using the packed-beds thickness as a characteristic dimension, which is the same for all evaluated conditions. It can be noted in Table 4 that in all temperatures, the effective diffusivity of leaves is higher than that of stems, reflecting the differences in the structure of these materials. At a given temperature, the diffusive resistance calculated for the stems is always higher than that of the leaves. For instance, at $40^{\circ} \mathrm{C}$, the resistance in drying the stems was about $25 \%$ higher in comparison to the leaves, at $50^{\circ} \mathrm{C}$ it was $100 \%$ higher, and at $60^{\circ} \mathrm{C}$ and $70^{\circ} \mathrm{C}$ it was $70 \%$ higher. 


\subsubsection{Empirical Model Based on ANN}

The model based on ANN technique can be obtained from a purely experimental database, without making assumptions that do not reflect the real behavior of the material during the drying process. For the ANN modeling, a total of 24 drying experiments were used, out of which 15 for fitting and 9 for verifying the robustness of neural network. Based on Equation (8), weights and biases for a network with 4 neurons were:

$$
\begin{aligned}
& I W=\left[\begin{array}{ccc}
-3.1395 & -11.2405 & 1.7887 \\
3.6839 & 0.5685 & -0.4299 \\
2.9787 & 0.6645 & -0.3926 \\
3.5918 & -0.2051 & 0.0725
\end{array}\right] b_{1}=\left[\begin{array}{c}
-8.6610 \\
1.5036 \\
1.5105 \\
4.3892
\end{array}\right] \\
& L W=\left[\begin{array}{llll}
0.1239 & 0.8023 & -1.4172 & -2.6439
\end{array}\right] b_{2}=\left[\begin{array}{l}
2.3685
\end{array}\right]
\end{aligned}
$$

The number of neurons (4) in the hidden layer found to this application was chosen by trial and error, as was suggested by Himmelblau [11].

Figure 9 shows the simulated estimations from the ANN, together with experimental points, for whole branches (a) and leaves (b) at the temperature of $60^{\circ} \mathrm{C}$, and for stems (c) at the temperature of $50^{\circ} \mathrm{C}$.

It can be seen that a good agreement between measured and estimated results was obtained using the artificial neural network.

Figure 10 shows the resulting correlation lines for the fitting database set. It can be withdrawn from Figure 10 that in the modeling using ANN, the neural network obtained to predict the moisture of branches and their fractions is versatile, since one single network was capable of predicting satisfactorily the moisture of the three materials in the range of temperatures evaluated. On the other hand, when using the modeling based on the Fick's second law, an effective diffusivity adjustment is required for every material (leaves, stems or branches) at each temperature. Moreover, the correlation factor $\left(\mathrm{R}^{2}\right)$ obtained in the ANN modeling (0.9956) is greater than that of the modeling based on the Fick's second law (about 0.92), which indicates that the ANN can predict better the drying kinetic of regular mint leaves, stems and branches. At this point, it can surely be said that the artificial neural network performance was much superior than that of the model based on the Fick's second law.

\section{Conclusion}

The results from this study showed that drying of leaves and stems are limited by diffusive mechanisms and owing to the differences in the morphological characteristic of the fractions, their drying rates are differently affected by the temperature, which leads to very distinct drying rates particularly for temperatures over $50^{\circ} \mathrm{C}$. Analysis of desorption behavior showed that stems and leaves have similar water binding properties, therefore the lower drying rates observed for stems are due to factors related to their shape and dimensions, which result in higher diffusive resistance in comparison to the leaves. Considering the conditions evaluated, the drying kinetics of branches were closer to those of the leaves. At each 


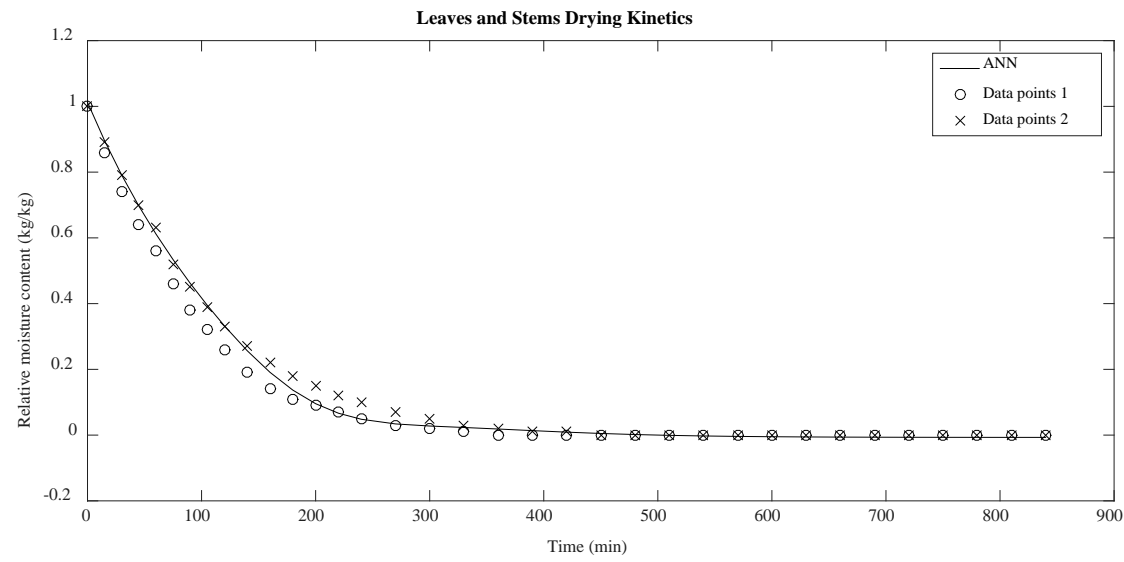

(a)

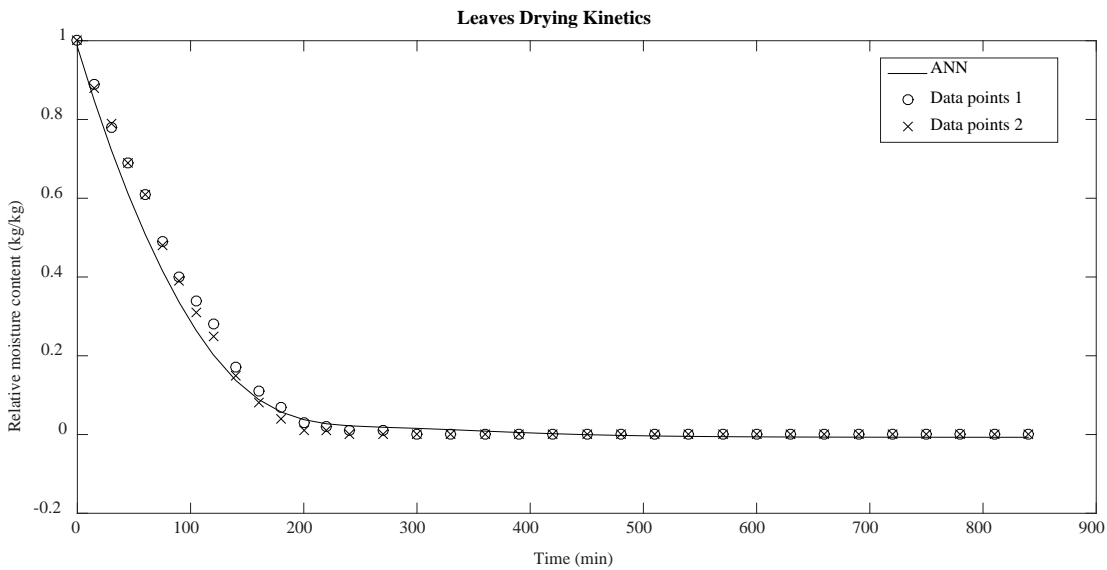

(b)

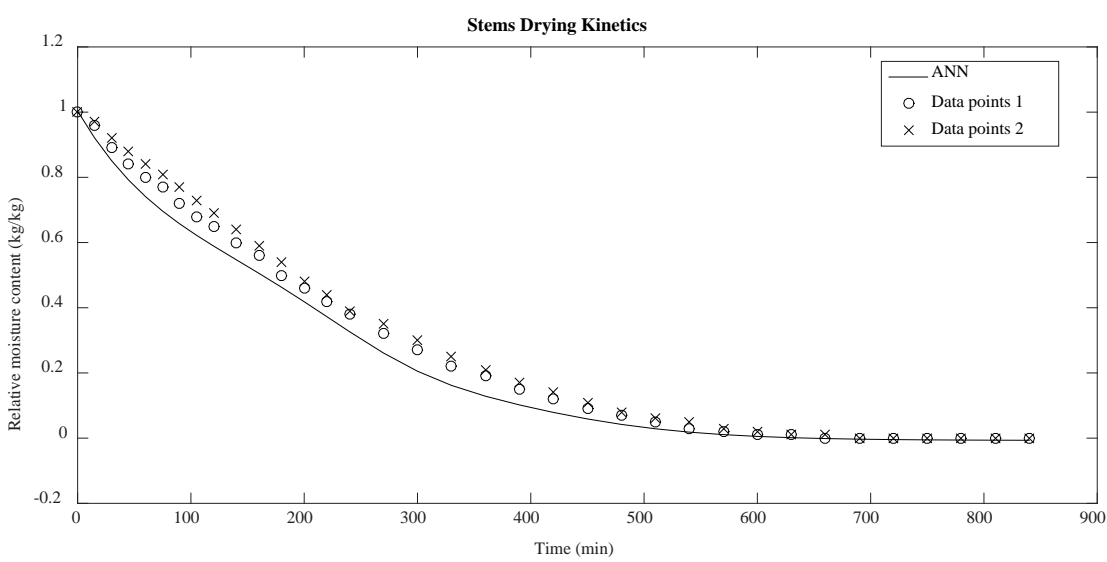

(c)

Figure 9. Verification results for (a) branches and (b) leaves drying kinetics at $60^{\circ} \mathrm{C}$, and for (c) stems drying kinetics at $50^{\circ} \mathrm{C}$.

temperature, effective diffusivities could be fitted from the kinetic data of stems, leaves and branches, but the use of a simplified approach that assumes a constant diffusivity for the whole process under a given temperature resulted in poor fittings for the conditions tested. Finally, although an artificial neural network and a model based on the Fick's second law of diffusion can be used to 


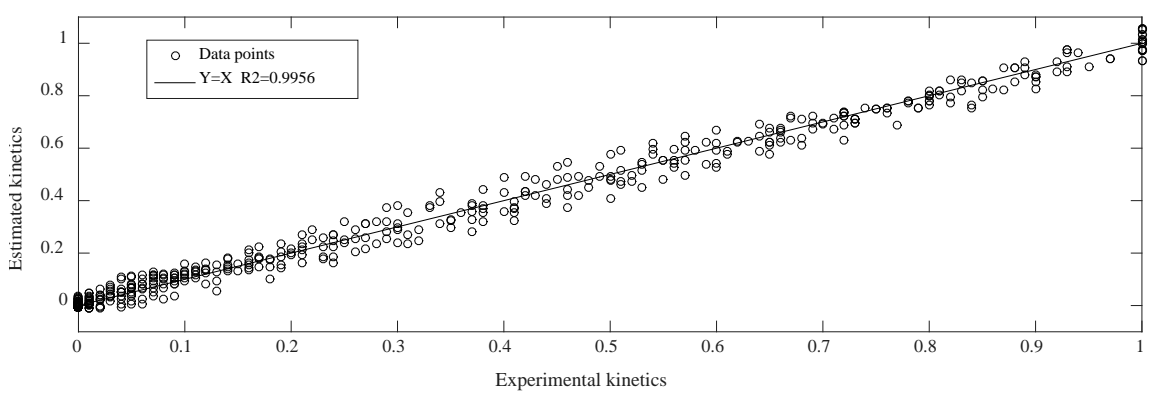

Figure 10. Drying kinetics fitting performance.

predict the drying kinetic of regular mint leaves, stems and branches in temperatures of $40^{\circ} \mathrm{C}, 50^{\circ} \mathrm{C}, 60^{\circ} \mathrm{C}$ and $70^{\circ} \mathrm{C}$, the artificial neural network performance was superior in all evaluated instances. An important advantage of this approach is that a single network is capable to predict the drying kinetics for the three materials over the whole range of experimental conditions evaluated.

\section{Acknowledgements}

The authors would like to thank Brazilian agencies CAPES and CNPq for the financial support.

\section{References}

[1] Chen, G. and Mujumdar, A.S. (2015) Drying of Herbal Medicines and Tea. In: Mujumdar, A.S., Ed., Drying Handbook, 4th Edition, Taylor and Francis Group, Abingdon-on-Thames, 637-646.

[2] Nayak, S., Kumar, A., Mishra, J. and Tiwari, G.N. (2011) Drying and Testing of Mint (Mentha piperita) by a Hybrid Photovoltaic-Thermal (PVT)-Based Greenhouse Dryer. Drying Technology, 29, 1002-1009.

https://doi.org/10.1080/07373937.2010.547265

[3] Quirijns, E.J., van Boxtel, A.J.B., van Loon, W.K.P. and van Straten, G. (2005a) An Improved Experimental and Regression Methodology for Sorption Isotherms. Journal of the Science of Food and Agriculture, 85, 175-185. https://doi.org/10.1002/jsfa.1773

[4] Erbay, Z. and Icier, F. (2010) A Review of Thin Layer Drying of Foods: Theory, Modeling and Experimental Results. Critical Reviews in Food Science and Nutrition, 50, 441-464. https://doi.org/10.1080/10408390802437063

[5] Díaz-Maroto, M.C., Pérez-Coello, M.S. and Cabezudo, M.D. (2002) Effect of Drying Method on the Volatiles in Bay Leaf (Laurus nobilis L.). Journal of Agricultural and Food Chemistry, 50, 4520-4524. https://doi.org/10.1021/jf011573d

[6] Szumny, A., Figiel, A., Gutiérrez-Ortíz, A. and Carbonell-Barrachina, Á.A. (2010) Composition of Rosemary Essential Oil (Rosmarinus officinalis) as Affected by Drying Method. Journal of Food Engineering, 97, 253-256.

https://doi.org/10.1016/j.jfoodeng.2009.10.019

[7] Tarhan, S., Telci, I., Tuncay, M.T. and Polatci, H. (2010) Product Quality and Energy Consumption When Drying Peppermint by Rotary Drum Dryer. Industrial Crops and Products, 32, 420-427. https://doi.org/10.1016/j.indcrop.2010.06.003

[8] Akpinar, E.K. (2006) Mathematical Modelling of Thin Layer Drying Processunder Open Sun of Some Aromatic Plants. Journal of Food Engineering, 77, 864-870. 
[9] Kaya, A. and Aydin, O. (2009) An Experimental Study on Drying Kinetics of Some Herbal Leaves. Energy Conversion and Management, 50, 118-124. https://doi.org/10.1016/j.enconman.2008.08.024

[10] Doymaz, I. (2006) Thin Layer Drying Behavior of Mint Leaves. Journal of Food Engineering, 74, 370-375.

[11] Himmelblau, D.M. (2008) Accounts of Experiences in the Application of Artificial Neural Networks in Chemical Engineering. Industrial and Engineering Chemistry Research, 47, 5782-5796. https://doi.org/10.1021/ie800076s

[12] Aghbashlo, M., Hosseinpour, S. and Mujumdar, A.S. (2015) Application of Artificial Neural Networks (ANNs) in Drying Technology: A Comprehensive Review. Drying Technology, 33, 1739-1462. https://doi.org/10.1080/07373937.2015.1036288

[13] Estiati, I., Freire, F.B., Freire, J.T., Aguado, R. and Olazar, M. (2016) Fitting Performance of Artificial Neural Networks and Empirical Correlations to Estimate Higher Heating Values of Biomass. Fuel, 180, 377-383.

https://doi.org/10.1016/j.fuel.2016.04.051

[14] Lira, T.S., Barrozo, M.A.S. and Assis, A.J. (2014) Air Quality Prediction in Uberlândia, Brazil, Using Linear Models and Neural Networks. Computer Aided Chemical Engineering, 24, 51-56.

[15] Freire, F.B., Vieira, G.N.A., Freire, J.T. and Mujumdar, A.S. (2014) Trends in Modelling and Sensing Approaches for Drying Control. Drying Technology, 32, 1524-1532. https://doi.org/10.1080/07373937.2014.925471

[16] Mateo, J.M., Cubillos, F.A. and Alvarez, P.I. (1999) Hybrid Neural Approaches for Modelling Drying Processes for Particulate Solids. Drying Technology, 17, 809-823. https://doi.org/10.1080/07373939908917571

[17] Freire, J.T., Freire, F.B., Ferreira, M.C. and Nascimento, B.S. (2012) A Hybrid Lumped Parameter; Neural Network Model for Spouted Bed Drying of Pastes with Inert Particles. Drying Technology, 30, 1342-1353. https://doi.org/10.1080/07373937.2012.684085

[18] Nascimento, B.S., Freire, F.B. and Freire, J.T. (2013) Neuronal and Grey Modelling of Milk Drying in Spouted Bed. Canadian Journal of Chemical Engineering, 91, 1815-1821. https://doi.org/10.1002/cjce.21886

[19] Costa, A.B.S., Freire, F.B., Ferreira, M.C. and Freire, J.T. (2014) Convective Drying of Regular Mint Leaves: Analysis Based on Fitting Empirical Correlations, Response Surface Methodology and Neural Networks. Acta Scientiarum Technology, 36, 271278. https://doi.org/10.4025/actascitechnol.v36i2.19238

[20] Movagharnejad, K. and Nikzad, M. (2007) Modeling of Tomato Drying Using Artificial Neural Network. Computers and Electronics in Agriculture, 59, 78-85. https://doi.org/10.1016/j.compag.2007.05.003

[21] Karimi, F., Rafiee, S., Taheri-Garavand, A. and Karimi, M. (2012) Optimization of an Air Drying Process for Artemisia absinthium Leaves Using Response Surface and Artificial Neural Network Models. Journal of the Taiwan Institute of Chemical Engineers, 43, 29-39. https://doi.org/10.1016/j.jtice.2011.04.005

[22] Zbicinski, I., Strumillo, P. and Kaminski, W. (1996) Hybrid Neural Model of Thermal Drying in a Fluidized Bed. Computers \& Chemical Engineering, 20, S695-S700. https://doi.org/10.1016/0098-1354(96)00125-1

[23] Association of Official Analytical Chemists (AOAC) (1990) Official Methods of Analysis of AOAC International. AOAC, Washington DC.

[24] Mohsenin, N.N. (1970) Physical Properties of Plant and Animal Materials. Gordon 
and Breach Science Publishers, New York.

[25] Labuza, T.P., Kaanane, A. and Chen, J.Y. (1985) Effect of Temperature on the Moisture Sorption Isotherms and Water Activity Shift of Two Dehydrated Foods. Journal of Food Science, 50, 385-391. https://doi.org/10.1111/j.1365-2621.1985.tb13409.x

[26] Greenspan, L. (1977) Humidity Fixed Points of Binary Saturated Aqueous Solutions. Journal of Research of the National Bureau of Standards-A Physics and Chemistry, 81A, 89-96. https://doi.org/10.6028/jres.081A.011

[27] Erbay, Z. and Icier, F. (2008) Thin-Layer Drying Behaviors of Olive Leaves (Olea europaea L.). Journal of Food Process Engineering, 33, 287-308. https://doi.org/10.1111/j.1745-4530.2008.00275.x

[28] Özbek, B. and Dadali, G. (2007) Thin-Layer Drying Characteristics and Modelling of Mint Leaves Undergoing Microwave Treatment. Journal of Food Engineering, 83, 541-549. https://doi.org/10.1016/j.jfoodeng.2007.04.004

[29] Crank, J. (1975) The Mathematic of Diffusion. Clarendon Press, Oxford.

[30] Quirijns, E.J., van Boxtel, A.J.B., van Loon, W.K.P. and van Straten, G. (2005) Sorption Isotherms, GAB Parameters and Isosteric Heat of Sorption. Journal of the Science of Food Agriculture, 85, 1805-1814. https://doi.org/10.1002/jsfa.2140

[31] Soysal, Y. and Öztekin, S. (2001) Comparison of Seven Equilibrium Moisture Content Equations for Some Medicinal and Aromatic Plants. Journal of Agricultural Engineering Research, 78, 57-63. https://doi.org/10.1006/jaer.2000.0636

[32] Lima-Corrêa, R.A.B., Ribeiro, K.C., Freire, J.T. and Ferreira, M.C. (2014) A Critical Analysis about Using of a Thin Layer Drying Concept to Model the Drying of Leaves. Proceedings of 19 th International Drying Symposium, Lyon, 24-27 August 2014, 1-8.

\section{Submit or recommend next manuscript to SCIRP and we will provide best} service for you:

Accepting pre-submission inquiries through Email, Facebook, LinkedIn, Twitter, etc. A wide selection of journals (inclusive of 9 subjects, more than 200 journals)

Providing 24-hour high-quality service

User-friendly online submission system

Fair and swift peer-review system

Efficient typesetting and proofreading procedure

Display of the result of downloads and visits, as well as the number of cited articles

Maximum dissemination of your research work

Submit your manuscript at: http://papersubmission.scirp.org/

Or contact aces@scirp.org 